\title{
Metal dihydride complexes: Photochemical mechanisms for reductive elimination
}

\author{
Robin N. Perutz \\ Department of Chemistry, University of York, York YO10 5DD, UK
}

\begin{abstract}
Most metal dihydride complexes with cis hydride ligands undergo photochemical reductive elimination of hydrogen. This class of reaction finds many applications as an entry point to highly reactive 16 -electron intermediates which undergo $\mathrm{C}-\mathrm{H}, \mathrm{Si}-\mathrm{H}$ or $\mathrm{H}-\mathrm{H}$ activation. The 16-electron intermediates can often be characterised by matrix isolation methods at low temperature or by time-resolved spectroscopy in solution. The group 8 metal dihydrides of the types $\mathrm{M}(\mathrm{dmpe})_{2} \mathrm{H}_{2}$, (dmpe $\left.=\mathrm{Me}_{2} \mathrm{PCH}_{2} \mathrm{CH}_{2} \mathrm{PMe}_{2}, \mathrm{M}=\mathrm{Fe}, \mathrm{Ru}, \mathrm{Os}\right)$, and $\mathrm{Ru}(\mathrm{CO})\left(\mathrm{PPh}_{3}\right)_{3} \mathrm{H}_{2}$ have all been studied by time-resolved absorption spectroscopy in conjunction with product studies. In each case, the transient 16-electron species is formed by photochemical loss of $\mathrm{H}_{2}$ within the risetime of the apparatus. The complex $\mathrm{Ru}(\mathrm{CO})\left(\mathrm{PPh}_{3}\right)_{3} \mathrm{H}_{2}$ has also been studied by time-resolved $\mathrm{IR}$ spectroscopy which demonstrates the reduction in oxidation state via the $\mathrm{CO}$ stretching frequency. Ultrafast spectroscopy of this complex with IR detection has been used to demonstrate that $\mathrm{H}_{2}$ elimination is complete within ca. $6 \mathrm{ps}$. Thus there is strong experimental evidence as well as theoretical arguments that the excited states of these complexes are dissociative with respect to loss of $\mathrm{H}_{2}$.
\end{abstract}

\section{INTRODUCTION}

Photolysis of many metal dihydride complexes of transition metals with mutually cis hydride ligands results in loss of molecular hydrogen. This reaction has provided one of the key entry points which allow access from 18-electron precursors to 16-electron intermediates capable of $\mathrm{C}-\mathrm{H}$ bond activation. The photochemical reaction causes a reduction in oxidation state of two and is a typical example of reductive elimination. The reverse reaction will usually proceed thermally and is the prototype example of an oxidative addition reaction. The basic reaction is shown in Figure 1 together with examples of photo-active dihydride complexes. In this article, I will summarise advances in knowledge of their photochemical mechanisms.

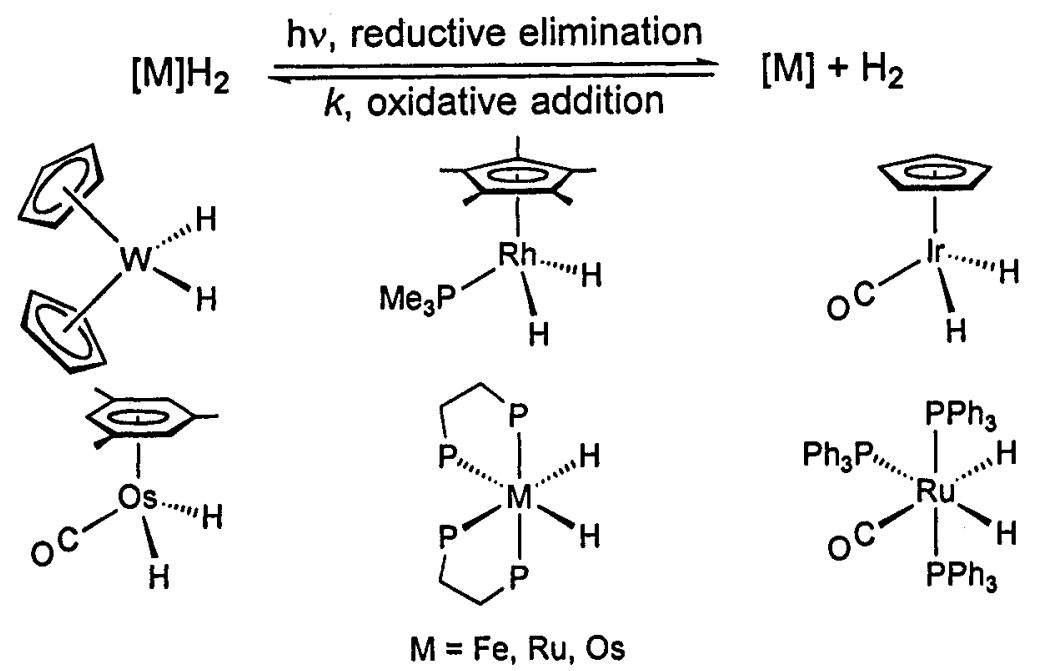

Figure 1. The basic photochemical reductive elimination of hydrogen and examples of photosensitive metal dihydride complexes

*Lecture presented at the 17th IUPAC Symposium on Photochemistry, Sitges, Barcelona, Spain, 19-24 July 1998. Other presentations are published in this issue, pp. 2147-2232. 
The importance of these reactions lies in their application to $\mathrm{C}-\mathrm{H}$ bond activation and, to a lesser extent, $\mathrm{Si}-\mathrm{H}$ activation. For instance, $\mathrm{W}\left(\eta^{5}-\mathrm{C}_{5} \mathrm{H}_{5}\right)_{2} \mathrm{H}_{2}$, one of the earliest examples, undergoes photochemical reaction with benzene to yield $\mathrm{W}\left(\eta^{5}-\mathrm{C}_{5} \mathrm{H}_{5}\right)_{2}(\mathrm{Ph}) \mathrm{H}$ (ref. 1, 2). It was through use of $\operatorname{Ir}\left(\eta^{5}\right.$ $\left.\mathrm{C}_{5} \mathrm{Me}_{5}\right)\left(\mathrm{PMe}_{3}\right) \mathrm{H}_{2}$ that Bergman demonstrated oxidative addition of alkanes (ref. 3 ). This entry point to $\mathrm{C}-\mathrm{H}$ activation of alkanes has also provided the means for many studies by Jones (ref. 4), Field, Green (ref. 5) Rest and Graham (ref. 6), and by my own research group, ref. 2, 7-14). These dihydride complexes do not undergo loss of hydrogen thermally. In contrast, the metal aryl hydride and alkyl hydride photoproducts are often less photosensitive than their dihydride precursors but may undergo reductive elimination of arene or alkane thermally (ref. 3,4 ). Photochemical reactions provide much readier access to study of the elementary steps of reactions than their thermal counterparts thanks to the availability of time-resolved spectroscopy. We have exploited this feature and used the photosensitivity of metal dihydride complexes to study the oxidative addition of hydrogen to the primary photoproducts, which ensues in the presence of excess hydrogen (ref. 7, 11-14).

\section{STEADY STATE STUDIES OF PHOTOCHEMICAL ELIMINATION OF HYDROGEN}

The first questions asked about a photochemical reaction often concern the UV/vis spectrum of the precursor and the quantum yield of reaction. Next in line, I usually anticipate a question about the nature of the electronic excited state from which the primary chemical step occurs: is it a ligand-field excited state or a charge-transfer excited state, is it a triplet or a singlet? After many years of study, the answers to these questions in the context of the photochemical elimination of hydrogen are very limited indeed. The UV/vis spectra show a few broad bands in the region below $320 \mathrm{~nm}$. In some cases, such as those of $\mathrm{M}(\mathrm{dmpe})_{2} \mathrm{H}_{2}$ $\left(\mathrm{M}=\mathrm{Ru}, \mathrm{Os}\right.$, dmpe $\left.=\mathrm{Me}_{2} \mathrm{PCH}_{2} \mathrm{CH}_{2} \mathrm{PMe}_{2}\right)$, the absorption simply rises steadily through the ultraviolet with no clear maxima at all. The variation in these spectra with metal and ancillary ligands is slight. The spectra of the final photoproducts are often equally devoid of information, but the 16-electron intermediates have very rich UV/vis spectra (see below). Initial information about quantum yields came from Geoffroy et al, who measured the quantum yields for loss of hydrogen from $W\left(\eta^{5}-\mathrm{C}_{5} \mathrm{H}_{5}\right)_{2} \mathrm{H}_{2}$ and its molybdenum analogue as ca. $10^{-2}$ and $10^{-1}$ respectively (photolysis at $366 \mathrm{~nm}$, ref. 15). More recently, Belt et al exploited the knowledge of the extinction coefficient of the primary photoproduct of $\mathrm{Ru}$ to obtain a quantum yield for loss of hydrogen from $\mathrm{Ru}(\mathrm{dmpe}){ }_{2} \mathrm{H}_{2}$ of $0.85 \pm 0.05$ via time-resolved spectroscopy (photolysis at $308 \mathrm{~nm}$, ref 16). However, there is no knowledge of the variation of the quantum yield with wavelength of photolysis.

In addition to his studies of quantum yields, Bradley et al. showed by means of labelling experiments with $\mathrm{Mo}\left(\eta^{5}-\mathrm{C}_{5} \mathrm{H}_{5}\right)_{2} \mathrm{H}_{2}$ in toluene- $\mathrm{d}_{8}$ that the reactions yield predominantly molecular hydrogen and not atomic hydrogen (ref. 15).

In case it is thought that the broad UV/vis bands of metal dihydride complexes mentioned above might be associated with the other ligands, it is worth contrasting the spectrum of $W\left(\eta^{5}-\mathrm{C}_{5} \mathrm{H}_{5}\right)_{2} \mathrm{H}_{2}$ with that of its photoproduct, $W\left(\eta^{5}-C_{5} H_{5}\right)_{2}$. The absorption spectrum of $W\left(\eta^{5}-C_{5} \mathrm{H}_{5}\right)_{2}$ exhibits a low energy LMCT band which shows clear vibrational fine structure (Figure 2a). This state is emissive, and the matrix absorption spectrum can be dramatically enhanced by recording it as a fluorescence excitation spectrum with a laser (Figure $2 \mathrm{~b}$, ref 16 ). The resulting spectrum probably still breaks the record for narrow absorption bands of a spin-allowed transition of an organometallic; the bands are ca. $10 \mathrm{~cm}^{-1}$ wide.

\section{THEORETICAL STUDIES OF PHOTOCHEMICAL REDUCTIVE ELIMINATION}

In order to make progress with understanding the nature of the excited state from which hydrogen is lost, it is helpful to draw on the extensive studies of metal carbonyl photochemistry. These investigations have shown that the a high quantum yield for $\mathrm{CO}$ loss is associated with population of a low lying ligand field state which is $\sigma$ antibonding with respect to $\mathrm{CO}$ (ref. 18). In contrast, those metal carbonyls in which the lowest excited state involves metal-to-ligand charge-transfer (e.g. to a substituted pyridine acting as an 




Figure 2. Spectra of $\mathrm{W}\left(\eta^{5}-\mathrm{C}_{5} \mathrm{H}_{5}\right)_{2}$ generated by irradiation of $\mathrm{W}\left(\eta^{5}-\mathrm{C}_{5} \mathrm{H}_{5}\right)_{2}$ in an argon matrix at $12 \mathrm{~K}$ (a) absorption spectrum, (b) excitation spectrum determined from variation in intensity of the $(0,1)$ emission band at $409.64 \mathrm{~nm}$ with excitation wavelength. The exciting source was an excimer-pumped, pulsed, dye laser. Reproduced with permission from ref. $16 \odot$ American Chemical Society.

ancillary ligand) have much reduced quantum yields for CO loss (ref. 19). By analogy, it is deduced that the loss of hydrogen from metal dihydride complexes occurs from ligand field excited states. It is straightforward to draw a plausible molecular orbital which is $\mathrm{M}-\mathrm{H}$ antibonding and $\mathrm{H}-\mathrm{H}$ bonding (designated $\sigma_{\mathrm{g}}{ }^{*}$, Figure 3 ),

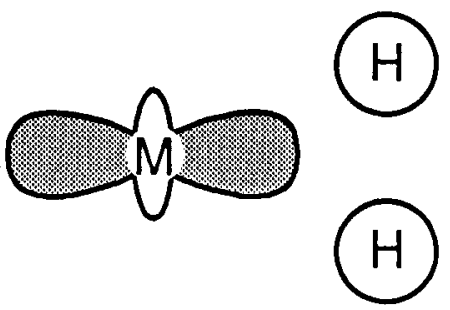

Figure 3. Overlap diagram showing $\sigma_{\mathrm{g}}{ }^{*}$ molecular orbital populated in the excited state which is $\mathrm{M}-\mathrm{H}$ antibonding and $\mathrm{H}-\mathrm{H}$ bonding.

but it is not obvious why this orbital should be populated so selectively especially when the UV/vis spectrum is so broad. Put in an alternative form, why does a metal carbonyl dihydride such as $\operatorname{Ir}\left(\eta^{5}-\mathrm{C}_{5} \mathrm{H}_{5}\right)(\mathrm{CO}) \mathrm{H}_{2}$ or $\mathrm{Ru}(\mathrm{CO})\left(\mathrm{PPh}_{3}\right)_{3} \mathrm{H}_{2}$ lose hydrogen in preference to $\mathrm{CO}$ ? Once more, we have to rely on a surmise, namely that the $\mathrm{H}$...H bonding interaction stabilises this unoccupied orbital sufficiently that it lies below the M...CO antibonding orbitals (or, more precisely, that the corresponding excited state is stabilised).

The challenge of providing a more thorough theoretical description of the photochemistry has been taken up by Veillard and Daniel (ref. 20 - 23). For instance, complexes of the type $\mathrm{ML}_{4} \mathrm{H}_{2}(\mathrm{M}=\mathrm{Fe}, \mathrm{Ru}, \mathrm{Os}$ ) with a d $\mathrm{d}^{6}$ electron configuration and a ${ }^{1} \mathrm{~A}_{1}$ ground state are shown to possess low-lying ${ }^{1} \mathrm{~B}_{2}$ and ${ }^{3} \mathrm{~B}_{2}$ excited states in which a molecular orbital is populated which is $\mathrm{M}$...H antibonding and $\mathrm{H}$...H bonding as illustrated in Figures 3. They also argue that these states are dissociative with respect to $\mathrm{ML}_{4}+\mathrm{H}_{2}$ as a consequence. The behaviour of $\mathrm{M}\left(\eta^{5}-\mathrm{C}_{5} \mathrm{Me}_{5}\right)\left(\mathrm{PMe}_{3}\right) \mathrm{H}_{2}(\mathrm{M}=\mathrm{Rh}, \mathrm{Ir})$ and related complexes is essentially the same as 
that of $\mathrm{ML}_{4} \mathrm{H}_{2}$ because of the isolobal relationship of the corresponding fragments. In the case of $\mathrm{W}\left(\eta^{5}\right.$ $\left.\mathrm{C}_{5} \mathrm{H}_{5}\right)_{2} \mathrm{H}_{2}$, the ground configuration is $\mathrm{d}^{2}$ and the ground state ${ }^{1} \mathrm{~A}_{1}$ This time a simple molecular orbital diagram suggests that the lowest lying excited state populates a $b_{2}$ orbital $\left(1,3 B_{2}\right.$ state) which should eliminate hydrogen atoms rather than an $\mathrm{H}_{2}$ molecule, while the next level populates the $\mathrm{a}_{1}$ orbital $\left(1,3 \mathrm{~A}_{1}\right)$ excited states) necessary for $\mathrm{H}_{2}$ elimination (Figure 4). ${ }^{*}$



Figure 4. Molecular orbital diagram for the frontier orbitals of $M\left(\eta^{5}-\mathrm{C}_{5} \mathrm{H}_{5}\right)_{2} \mathrm{H}_{2}(\mathrm{M}=\mathrm{Mo}, \mathrm{W})$ highlighting the bonding of the hydride ligands. The arrows show the allowed transitions which populate $\mathrm{M}-\mathrm{H}$ antibonding orbitals. Only population of the upper orbital (leading to an $A_{1}$ excited state) simultaneously makes the H-H bond. Adapted with permission from J. W. Lauher and R. Hoffmann, J. Am. Chem. Soc. 98, 1729. (1976) @ American Chemical Society.

Daniel takes these arguments considerably further in her calculations of the potential energy curves for $\mathrm{Fe}(\mathrm{CO})_{4} \mathrm{H}_{2}$ and its dissociation derived by the CASSCF method (Complete Active Space Self Consistent Field, ref. 21a). We now see a cluster of excited states none of which show a minimum (Figure 5). At approximately $1.4 \AA \mathrm{Fe} . . . \mathrm{H}_{2}$ separation, two pairs of states undergo avoided crossings. Daniel identifies two channels for dissociation. In one of the excited states, $\mathrm{H}_{2}$ is released together with excited $\mathrm{Fe}(\mathrm{CO})_{4}$ via a ${ }^{1} \mathrm{~A}_{1}$ potential curve. In the other, the $\mathrm{Fe}(\mathrm{CO})_{4}$ is formed in its ground ${ }^{3} \mathrm{~B}_{2}$ state via initial population of a ${ }^{1} B_{2}$ state and intersystem crossing. This has an energy barrier of ca. $40 \mathrm{~kJ} \mathrm{~mol}^{-1}$ according to the calculations. A further step has recently been taken by Heitz and Daniel (ref. 21b) who have studied the propagation of wavepackets (see below) on the calculated potential energy surfaces for the ground and excited states of $\mathrm{Fe}(\mathrm{CO})_{4} \mathrm{H}_{2}$ corresponding either to $\mathrm{CO}$ or $\mathrm{H}_{2}$ elimination. These calculations include further excited states and make allowance for spin-orbit coupling. The simulations of the dynamics of dissociation show that two excited states, ${ }^{1} B_{1}$ and ${ }^{1} A_{1}$, undergo ultrafast dissociation within $40 \mathrm{fs}$ ( $1 \mathrm{fs}=$ $10^{-15} \mathrm{~s}$ ). Both excited states arise, to first order, from transitions between occupied $d$ orbitals and the $\sigma_{\mathrm{g}}{ }^{*}$ orbital of the type shown in fig. 3. Of particular interest, is the prediction that $\mathrm{CO}$ dissociation also occurs in ca. $100 \mathrm{fs}$ and that the ratio of quantum yields for $\mathrm{H}_{2}$ elimination and $\mathrm{CO}$ elimination (the branching ratio) increases from about 10 on irradiation into the low energy tail of the absorption band, to about 50 on the high energy side. Intersystem crossing is not predicted to be competitive with direct dissociation from singlet states. That $\mathrm{Fe}(\mathrm{CO})_{4} \mathrm{H}_{2}$ does lose $\mathrm{H}_{2}$ on photolysis has been demonstrated by Sweany; however, no elimination of $\mathrm{CO}$ was observed experimentally (ref. 24). Thus the theoretical methods paint a complex

\footnotetext{
"Daniel and Veillard (ref. 23) criticise our comments in ref. 2 about the states which lead to $\mathrm{H}_{2}$ elimination from W( $\eta^{5}$. $\left.\mathrm{C}_{5} \mathrm{H}_{5}\right)_{2} \mathrm{H}_{2}$ thinking that we implicated the ${ }^{1,3} \mathrm{~B}_{2}$ and ${ }^{1,3} \mathrm{~A}_{1}$ states. A more careful reading shows that there is no disagreement. They are also concerned that we phrased our argument in terms of molecular orbitals rather than electronic states. Since the ground electronic state is totally symmetric and all states are non-degenerate in $C_{2 v}$ symmetry, there is no difference between orbitals and states at this qualitative level. Additionally, spin-orbit coupling enables any spin-state changes to occur readily and mixes spin states extensively.
} 
picture of photochemical reductive elimination which is hard to transfer to other molecules, yet the relation to the qualitative arguments still stands. On the other hand, the predictions can be tested with modern methods, viz. that there should be two excited states which undergo immediate dissociation and that the branching ratio between $\mathrm{H}_{2}$ and $\mathrm{CO}$-elimination should be wavelength dependent.

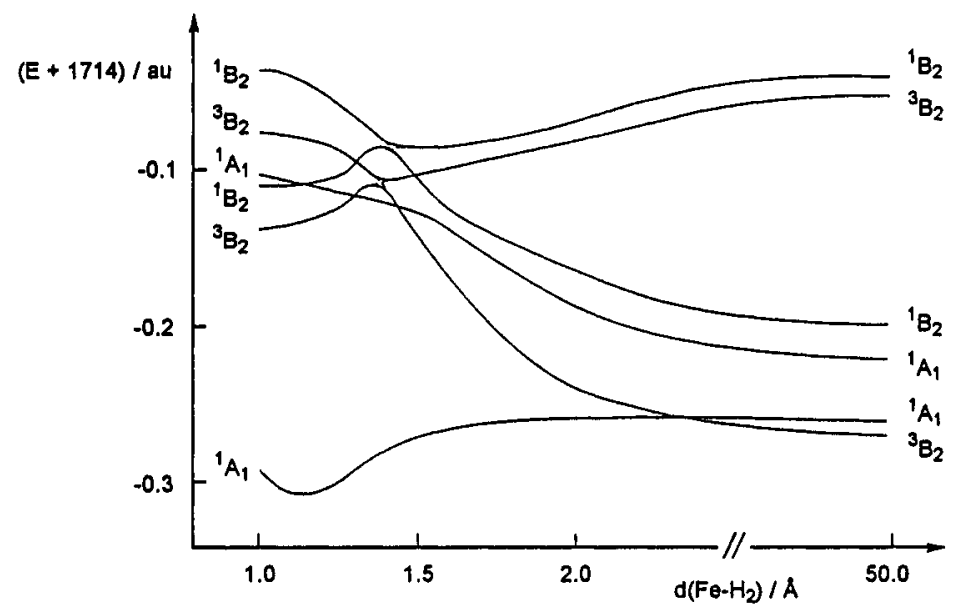

Figure 5. Potential energy curves for the ground state of $\mathrm{Fe}(\mathrm{CO})_{4} \mathrm{H}_{2}$ and the excited states leading to photodissociation of hydrogen calculated by the CASSCF method Adapted with permission from ref. 21 (C) American Chemical Society.

\section{STUDIES OF REDUCTIVE ELIMINATION BY TIME-RESOLVED SPECTROSCOPY}

Our early studies of photochemical reductive elimination employed matrix isolation which allowed us to characterise the 16-electron photoproduct (e.g. $\mathrm{Mo}\left(\eta^{5}-\mathrm{C}_{5} \mathrm{H}_{5}\right)_{2}$ from $\mathrm{Mo}\left(\eta^{5}-\mathrm{C}_{5} \mathrm{H}_{5}\right)_{2} \mathrm{H}_{2}$ ) with high resolution spectrometers (ref. 2). Since low temperature matrices do not stabilise excited states, it is possible to guarantee that such a spectrum belongs to the ground state of a reaction intermediate and not to an excited state. More recently, we have combined the matrix studies with time-resolved spectroscopy in solution. The matrix studies act as a very effective complement to time-resolved spectroscopy in solution for which the above guarantee is not possible. The first example was for molybdenocene itself (ref. 25), but the complementarity of the methods is best illustrated by the matrix and time-resolved spectra of Ru(dmpe ${ }_{2}$ formed by photolysis of $\mathrm{Ru}\left(\mathrm{dmpe}{ }_{2} \mathrm{H}_{2}\right.$ (Figure 6 , ref. 7,26 ). We have now studied a range of metal dihydride complexes by these techniques with nanosecond lasers in solution (ref. 11-14). These experiments invariably show that reductive elimination is complete within the instrumental risetime of a few tens of nanoseconds.

In order to proceed further, we needed to turn to ultrafast spectroscopy, i.e. time-resolved spectroscopy with picosecond and femtosecond lasers. In our first successful attempt, we exploited the rich spectrum of $\mathrm{Ru}$ (dmpe) $)_{2}$ (Figure 6) and the reversibility of the photoreaction of $\mathrm{Ru}(\mathrm{dmpe})_{2} \mathrm{H}_{2}$ under a hydrogen atmosphere (ref. 27). We showed that the transient absorbance measured at a wavelength close to the absorption maxima of $\mathrm{Ru}(\mathrm{dmpe})_{2}$ rose to its maximum value within the instrumental risetime of ca. $16 \mathrm{ps}$. The implication was that both $\mathrm{Ru}-\mathrm{H}$ bonds were cleaved, the $\mathrm{H}-\mathrm{H}$ bond formed and the $\mathrm{RuP}_{4}$ skeleton bent back to form square planar $\mathrm{Ru}(\mathrm{dmpe})_{2}$ within a few picoseconds. However, we were not able to obtain a full $U V / v i s$ spectrum after the laser pulse because of the limitations of the apparatus. In subsequent experiments on the related $\mathrm{Ru}$ (depe) ${ }_{2} \mathrm{H}_{2}$, we employed a laser with a much shorter pulse. This time we were able to show that the transient absorption rose to its maximum value within ca. 1 ps. However, the quality of the spectra was reduced because the tightly focused, high repetition rate laser causes decomposition even when the solutions are flowed through the sample cell under a hydrogen atmosphere. 
If we were to test the postulate of dissociative reductive elimination more stringently we needed to turn to $\mathbb{R}$ spectroscopy. For that purpose, we required a precursor with a carbonyl group in addition to the hydride ligands, since the $\mathrm{CO}$ stretching frequency can report on the oxidation state of the metal. We turned to one of the complexes which Geoffroy had studied very early on (ref. 28), $\mathrm{Ru}(\mathrm{CO})\left(\mathrm{PPh}_{3}\right)_{3} \mathrm{H}_{2}$, a complex which is far easier to synthesise and handle than $\mathrm{Ru}(\mathrm{dmpe})_{2} \mathrm{H}_{2}$. The first stage was to investigate its photochemistry by time-resolved UV/vis and IR spectroscopy with nanosecond lasers (ref. 14). Flash photolysis with UV/vis detection revealed a transient photoproduct formed within the rise time of the apparatus. The first order rate constant for its decay increases linearly with concentration of dissolved hydrogen. Flash photolysis with infrared detection (Time-Resolved Infrared or TRIR spectroscopy) demonstrated immediate ( $<500 \mathrm{~ns}$ ) bleaching of the CO stretching band of the precursor at $1940 \mathrm{~cm}^{-1}$ and growth of a transient absorbing at $1845 \mathrm{~cm}^{-1}$ which decayed with kinetics consistent with the UV/vis experiments (Figure 7). The very large shift of ca. $100 \mathrm{~cm}^{-1}$ in $v(\mathrm{CO})$ from precursor to product is a striking demonstration that reductive elimination has occurred. Thus the product can be assigned as $\mathrm{Ru}\left(\mathrm{PPh}_{3}\right)_{3} \mathrm{CO}$ (eq 1). Unfortunately, we cannot determine whether this species has a square planar structure like Ru(dmpe) ${ }_{2}$.

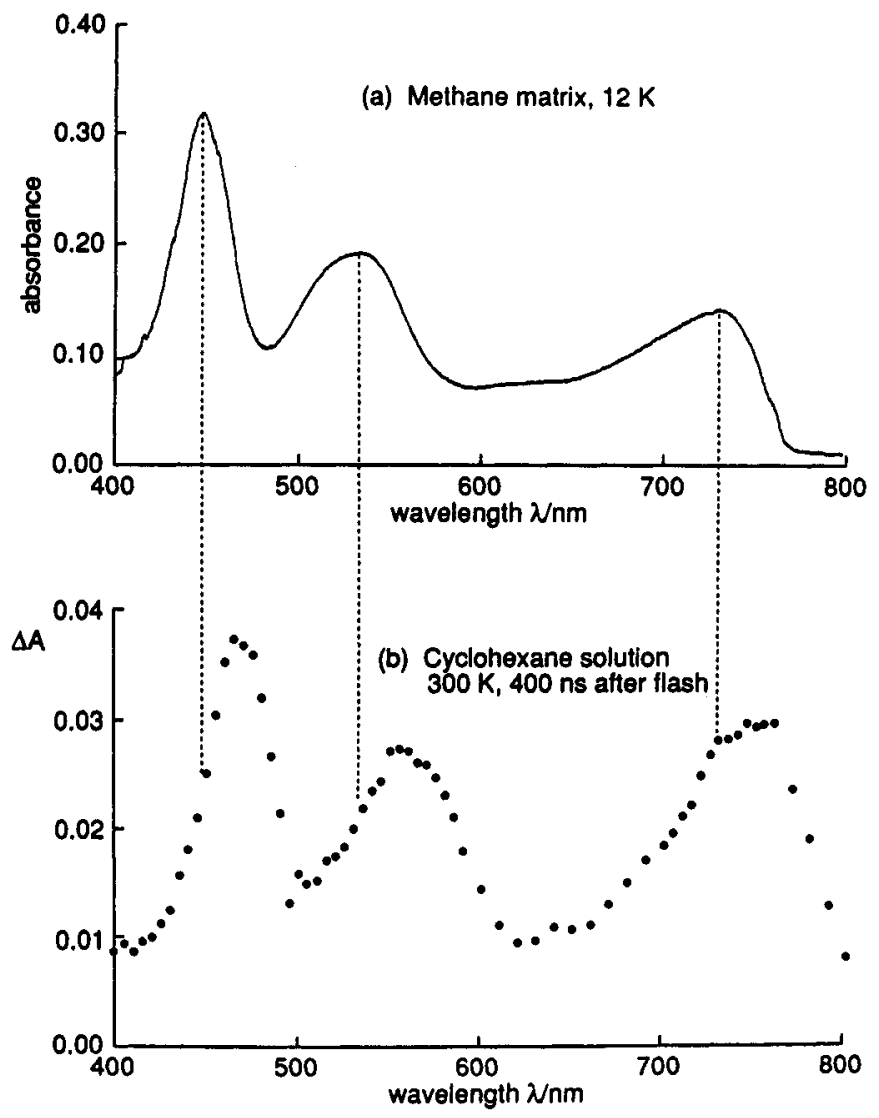

Figure 6. Spectra of $\mathrm{Ru}$ (dmpe) ${ }_{2}$ obtained by photolysis of $\mathrm{Ru}(\mathrm{dmpe})_{2} \mathrm{H}_{2}$ (a) conventional spectrum in methane matrix at $12 \mathrm{~K}$ (b) transient spectrum $400 \mathrm{~ns}$ after laser flash photolysis $(308 \mathrm{~nm})$ in cyclohexane solution at $300 \mathrm{~K}$. Reproduced with permission from Ref. 26 ( American Chemical Society

These experiments gave us the basis for ultrafast spectroscopy of $\mathrm{Ru}(\mathrm{CO})\left(\mathrm{PPh}_{3}\right)_{3} \mathrm{H}_{2}$. While nanosecond TRIR spectroscopy can be carried out with an excimer laser as the exciting source and a continuous diode laser to monitor the IR absorption, ultrafast TRIR spectroscopy needs a different technique (ref. 29). In our experiments, the principal source is a $608 \mathrm{~nm}$ laser beam giving pulses lasting $4 \mathrm{ps}$ which are repeated 1000 times per second. Part of this beam is split off and frequency doubled to provide the UV photolysis beam. We employed relatively low energy photolysis pulses of about $1-2 \mu \mathrm{J}$ per pulse. The IR source is also a 
continuous diode laser, but this time it is detected via upconversion, i.e. by non-linear mixing with the visible laser beam. In the ultrafast experiment the time delay has to be generated optically rather than with
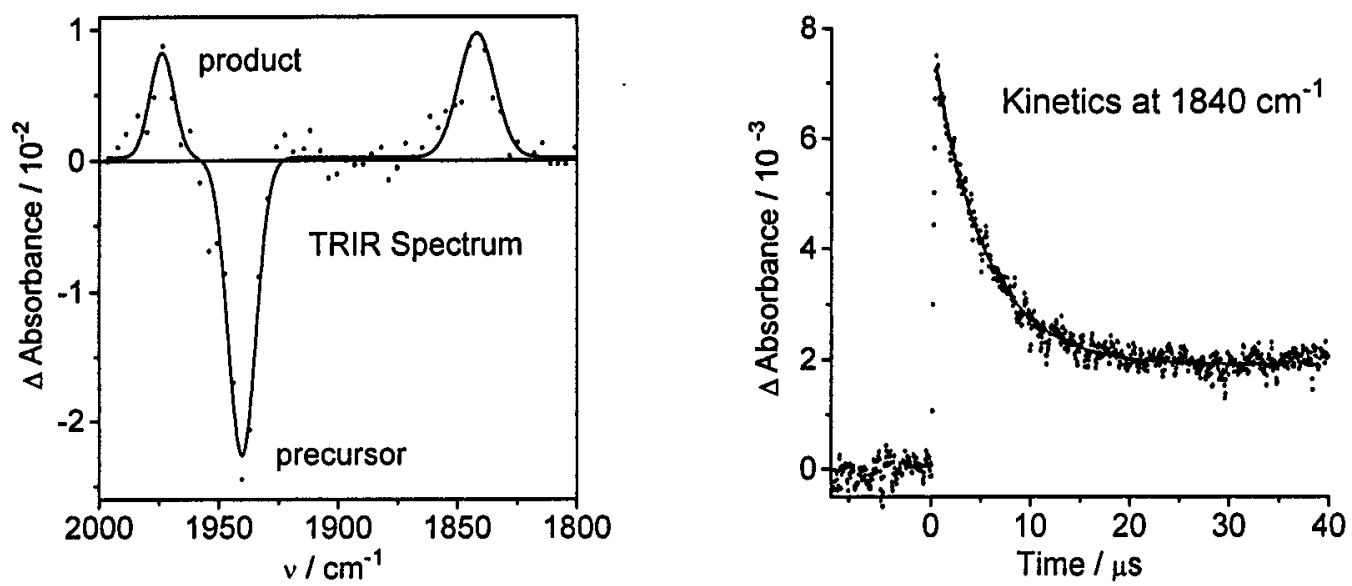

Figure 7. (a) Microsecond TRIR spectrum recorded $1 \mu$ s after laser flash photolysis (laser wavelength 355 $\mathrm{nm})$ of $\mathrm{Ru}(\mathrm{CO})\left(\mathrm{PPh}_{3}\right)_{3} \mathrm{H}_{2}$ dissolved in benzene- $\mathrm{d}_{6}$ under 1 atm $\mathrm{H}_{2}$. The negative feature is due to bleaching of the precursor, the positive features are due to photoproducts. The band at $1845 \mathrm{~cm}^{-1}$ is due to $\mathrm{Ru}\left(\mathrm{PPh}_{3}\right)_{3} \mathrm{CO}$, the band at $1974 \mathrm{~cm}^{-1}$ is due to a long-lived secondary product. (b) Transient formation and decay of $\mathrm{Ru}\left(\mathrm{PPh}_{3}\right)_{3} \mathrm{CO}$ monitored at $1840 \mathrm{~cm}^{-1}$. Reproduced with permission from ref. $14 \odot$ Royal Society of Chemistry

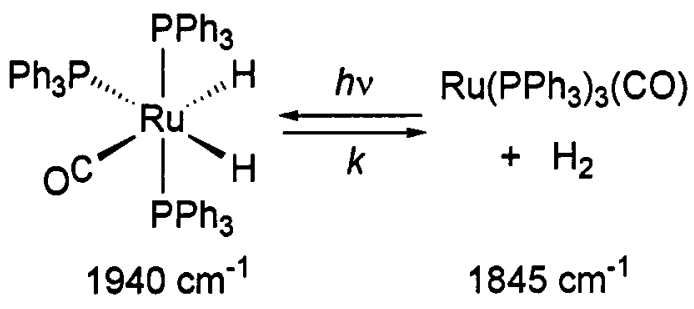

\section{Equation 1}

Metal Dihydride Complexes: Photochemical Mechanisms for Reductive Elimination

an oscilloscope, so the data are collected point-by-point both in the wavenumber and the time dimensions. In both types of experiment, the sample is dissolved in deuterobenzene and flowed through the sample cell in a closed loop.

With the ultrafast equipment, we again detect bleaching of the precursor signal at ca. $1940 \mathrm{~cm}^{-1}$ and rise of the product signal at ca. $1840 \mathrm{~cm}^{-1}$ (ref. 14). After an initial spike (due to the solvent response) during the instrumental risetime of ca. $6 \mathrm{ps}$, the signals maintain a steady amplitude for at least $4 \mathrm{~ns}$, the longest delays achievable with the apparatus (Figure 8). Thus the ultrafast experiments provide unambiguous evidence that reductive elimination is complete within 6 ps of excitation: bond breaking and making is complete. Often photodissociation reactions of metal carbonyls result in fragments which are vibrationally excited which return to their vibrational ground state over tens or hundreds of picoseconds. In this case, there isn't any evidence for vibrational cooling of the $\mathrm{CO}$ within the photofragment: the $\mathrm{CO}$ group is already in its ground vibrational state after 6 ps. Probably, much of the excess energy of the reaction is taken away as vibrational and rotational excitation of expelled hydrogen. 


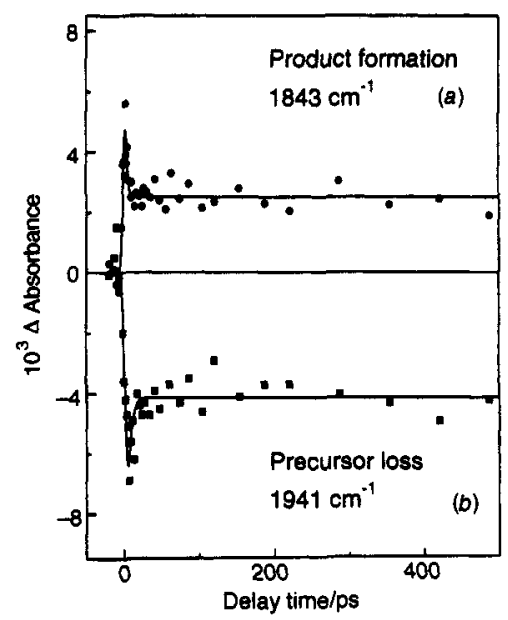

Figure 8. Ultrafast TRIR kinetics following laser photolysis of $\mathrm{Ru}\left(\mathrm{PPh}_{3}\right)_{3}(\mathrm{CO}) \mathrm{H}_{2}$ in benzene- $\mathrm{d}_{6}$ under $\mathrm{H}_{2}$ (laser wavelength $304 \mathrm{~nm}$ ) (a) at $1843 \mathrm{~cm}^{-1}$ showing formation of $\mathrm{Ru}\left(\mathrm{PPh}_{3}\right)_{3}(\mathrm{CO})$, (b) at $1941 \mathrm{~cm}^{-1}$ showing bleaching of $\mathrm{Ru}\left(\mathrm{PPh}_{3}\right)_{3}(\mathrm{CO}) \mathrm{H}_{2}$. The very fast component in both traces lasting ca. $6 \mathrm{ps}$ lies within the instrumentals response. Reproduced with permission from ref. 14 ○ Royal Society of Chemistry

At this stage we are therefore close to demonstrating experimentally that the excited states of this dihydride complex are dissociative with respect to elimination of hydrogen. Veillard and Daniel's key conclusion from theory is vindicated: that irradiation of metal dihydride complexes populates an excited state which is dissociative with respect to hydrogen loss. Photochemical reductive elimination of hydrogen joins a growing number of surprisingly specific photoprocesses of complex molecules which reach completion within femtoseconds or a few picoseconds. Examples include electrocyclic rearrangements of cyclic alkenes and dienes (ref. 30), formation of $\mathrm{Cr}(\mathrm{CO})_{5}$ from $\mathrm{Cr}(\mathrm{CO})_{6}$ (ref. 31), spin-state conversion of $\left[\mathrm{Fe}(\mathrm{bpy})_{3}\right]^{2+}$ (bpy $=2,2^{\prime}$-bipyridyl) (ref. 32), and transfer of coordinated $\mathrm{CO}$ from iron to copper in cytochrome $c$ oxidase (ref. 33). Although these processes can be described by the typical language of discrete states, internal conversion and intersystem crossing employed by most authors, there are problems in understanding the specificity of product distribution. Spectroscopists have developed an alternative language for describing photoprocesses in small molecules, that of the wavepacket and vibrational coherence which is much more appropriate to the non-stationary state in which dissociation occurs (ref. 30 , 34). In this language, the initial laser pulse promotes the sample to an excited state so rapidly that the ground state geometry is retained (Franck-Condon principle), creating an excited state wavepacket which then evolves on the excited-state potential-energy surface. If the excited state is bound, the wavepacket evolves in an oscillatory fashion as the molecule vibrates: a Fourier transform of these oscillations gives the frequencies of the normal modes which are excited. The oscillations are damped because the initial coherence of the motion is lost as the vibrations lose their relative phase (vibrational dephasing). If the excited state is dissociative, the wavepacket moves across the repulsive surface on the normal coordinate which effects dissociation and the fragment is expelled coherently (Figure 9). Once again vibrations are excited corresponding to the modes involved in the dissociation process. These events can be followed in real time by irradiating with a femtosecond pump pulse and probing with a second pulse delayed by a few tens of femtoseconds.

Mathies et al. have summarised the nature of photochemistry eloquently in the context of electrocyclic ring opening reactions of alkenes (ref. 30):

'Photochemical reactions occur because a molecule's nuclear framework evolves under the influence of the altered excited state electronic potential. This evolution can be described as a combination of motions along individual normal modes. Therefore mode specific knowledge of the geometry changes that occur upon electronic excitation reveals how the molecule begins its journey from reactant to product.' 


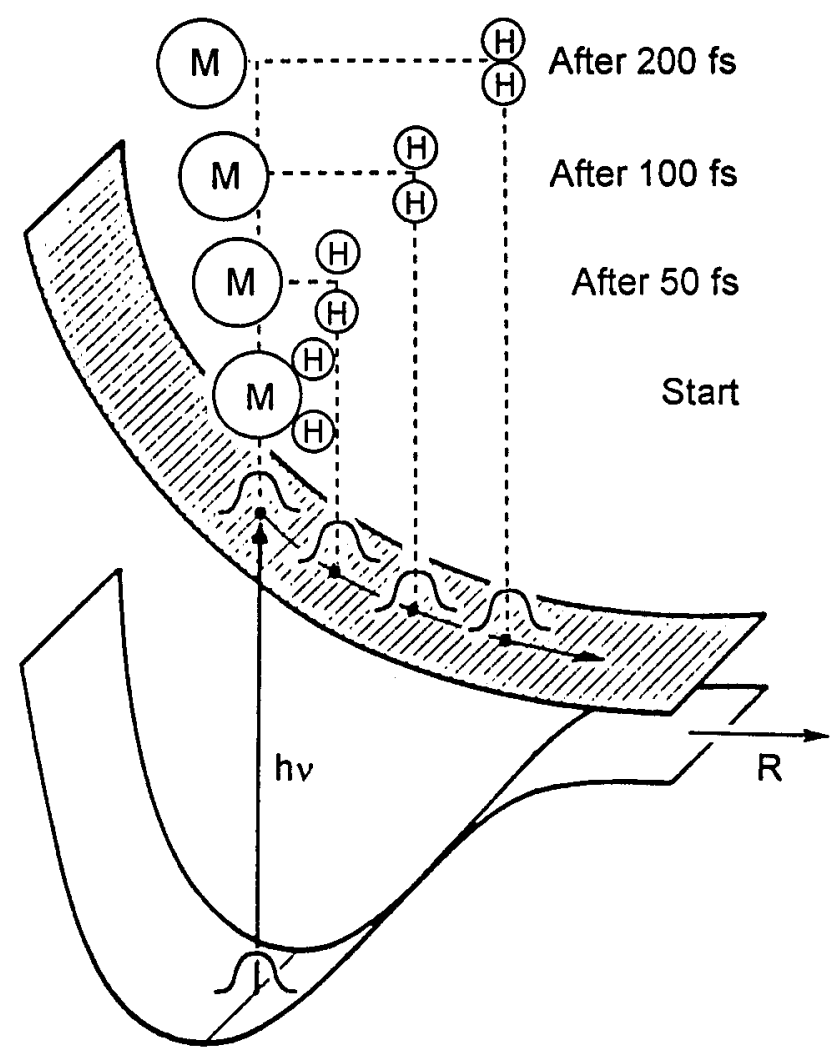

Figure 9. Cartoon view of photofragmentation of a metal dihydride complex. The lower surface represents a strip of the potential energy surface as a function of $\mathrm{M}_{\text {. }} \mathrm{H}_{2}$ separation. The absorption of light transfers the molecule to the upper repulsive surface. At the start of reaction the fragments are still in contact, but they move apart within a few hundred femtoseconds. Adapted with permission from M. Rosker, M. Dantus and A. H. Zewail. Science 241, 1200 (1988).

They go on to show that the stereochemistry of reaction is established in the Franck-Condon region, i.e. prior to any significant relaxation. Appropriate timescales are now tens and hundreds of femtoseconds, 50 times shorter than those we have employed. A good example of oscillatory behaviour in a complex molecule undergoing photodissociation comes from studies of nitrosyl myoglobin (ref. 35) which show how the ironhistidine vibration and the doming vibration of the haem are excited together at the same time as NO is expelled. It is also possible to address the question of concertedness of reaction: are bonds really made and broken simultaneously? We may look forward then to acquiring knowledge of the inner workings of hydride photochemistry at an altogether different level as chemists discover how the new ultrafast methods can be applied to metal hydride photochemistry.

\section{ACKNOWLEDGEMENTS}

I would like to thank all those who have worked with me, first in Oxford and then in York, on the photochemistry of metal dihydride complexes, especially Mirco Colombo, Peter Grebenik, Jeremy Hill, Carmen Nicasio, Robert Osman, Martin Partridge, David Pattison, Denise Rooney, Mike Whittlesey and those from other institutions who have collaborated with me including Claudio Bianchini, Odile Eisenstein, Mike George, Bill Jones, Stuart Macgregor, Maurizio Peruzzini. The work would not have been possible without the contributions from colleagues in York: Ron Hester, Roger Mawby and John Moore. It was John Moore who led the ultrafast IR experiments and advised me on the theory of photodissociation. 


\section{REFERENCES}

1. C. Giannotti and M. L. H. Green. J. Chem. Soc., Chem. Commun. 1114 (1972).

2. P. Grebenik, R. Grinter and R. N. Perutz. Chem. Soc. Rev. 17, 453 (1988) and references therein.

3. B. Amdtsen, R. G. Bergman, T. A. Mobley and T. H. Peterson. Acc. Chem. Res. 28, 154 (1995) and references therein.

4. W. D. Jones and F. J. Feher. Acc. Chem. Res. 22, 91, (1989). R. M. Chin, L. Dong, S. B. Duckett, M. G. Partridge, W. D. Jones and R. N. Perutz, J. Am. Chem. Soc. 1157685 (1993).

5. L. Labella, A. Chernaga and M. L. H Green. J. Chem. Soc., Dalton Trans. 395 (1995). L. D. Field; A. V. George and B. A. Messerle. J. Chem. Soc., Chem. Commun. 133 (1991).

6. P. E. Bloyce, A. J. Rest, I. Whitwell. J. Chem. Soc., Dalton Trans. 813 (1990). P. E. Bloyce, A. J. Rest, I. Whitwell, W. A. G. Graham and R. Holmes-Smith. J. Chem. Soc., Chem. Commun. 846 (1988).

7. R. N. Perutz. Chem. Soc. Rev. 21, 361 (1993) and references therein.

8. M. G. Partridge, A. McCamley and R. N. Perutz. J. Chem. Soc., Dalton Trans. 3519 (1994).

9. S. A. Brough, C. Hall, A. McCamley, R. N. Perutz, S. Stahl, U. Wecker, and H. Werner. J. Organomet. Chem. 504, 33 (1995).

10. R. J. Mawby, R. N. Perutz and M. K. Whittlesey. Organometallics 14, 3268 (1995).

11. L Cronin, M. C. Nicasio, R. N. Perutz, R. G. Peters, D. M. Roddick and M. K. Whittlesey. J. Am. Chem. Soc. 117,10047 (1995).

12. M. C. Nicasio, R. N. Perutz and P. H. Walton. Organometallics 16, 1410 (1997).

13. R. Osman, D. I. Pattison, R. N. Perutz, C. Bianchini, J. A. Casares and M. Peruzzini. J. Am. Chem. Soc. 119, 8459 (1997).

14. M. Colombo, M. W. George, J. N. Moore, D. I. Pattison, R. N. Perutz, I. G. Virrels and T. Q. Ye, J. Chem. Soc., Dalton Trans. 2857 (1997).

15. G. L. Geoffroy and M. G. Bradley, Inorg. Chem. 17, 2410 (1978).

16. J. N. Hill, R. N. Perutz and A. D. Rooney, J. Phys. Chem. 99, 538 (1995).

17. G. L. Geoffroy and M. S. Wrighton. Organometallic Photochemistry, p.48 Academic Press, New York (1979). See also, for example, A. G. Joly and K. A. Nelson. Chem. Phys. 152, 69 (1991).

18. A. J. Lees, Chem. Rev. 87, 711 (1987).

19. S. T. Belt, J. C. Scaiano and M. K. Whittlesey. J. Am. Chem. Soc. 115, 1921 (1993).

20. A. Veillard. Nouv. J. Chim. 5, 599 (1981).

21. (a) C. Daniel. J. Phys. Chem. 95, 2394 (1991). (b) M. C. Heitz and C. Daniel. J. Am. Chem. Soc. 119,8269 (1997).

22. A. Veillard. In Photoprocesses in Transition Metal Complexes, Biosystems and other Molecules. Experiment and Theory (E. Kochanski, ed) pp 173-216. Kluwer, Dordrecht 1992.

23. C. Daniel and A. Veillard In Transition Metal Hydrides (A. Dedieu, ed) pp 235-262. VCH New York 1992.

24. R. L. Sweany. J. Am. Chem. Soc. 103, 2410 (1981).

25. R. N. Perutz and J. C. Scaiano, J. Chem. Soc., Chem. Commun. 1984, 457.

26. C. Hall, W. D. Jones, R. J. Mawby, R. Osman, R. N. Perutz, M. K. Whittlesey. J. Am. Chem. Soc. 114, 7425 (1992).

27. R. Osman, R. N. Perutz, A. D. Rooney and A. J. Langley. J. Phys. Chem. 98, 3562 (1994).

28. G. L. Geoffroy and M. G. Bradley. Inorg. Chem. 16, 744 (1977).

29. T. Q. Ye, C. J. Arnold, D. I. Pattison, C. L. Anderton, D. Dukic, R. N. Perutz, R. E. Hester and J. N. Moore. Appl. Spec. 50, 597 (1996).

30. M. K Lawless,. S. D. Wickham and R.A. Mathies. Acc. Chem. Res. 28, 493 (1995).

31. S. A Trushin, W. Fuss, W. E. Schmid and K. L. Kompa J. Phys. Chem. A. 102, 4129 (1998).

32. J. K. McCusker, K. N. Walda, R. C. Dunn, J. D. Simon, D. Magde and D. N. Hendrickson. J. Am. Chem. Soc. 115, 298 (1993).

33. R. B. Dyer, K. A. Peterson, P. O. Stoutland and W. H Woodruff. Biochemistry 33, 500 (1994).

34. A. H. Zewail. Laser Physics 5, 417 (1995).

35. L. Zhu, J. T. Sage and P. M. Champion. Science 266, 629 (1994). 